\title{
FINDING PEACE ON A PSYCHIATRIC WARD WITH YOGA: REPORT ON A PILOT ANTHROPOLOGICAL STUDY IN PONDICHERRY, INDIA
}

Krzysztof Bierski, Postdoctoral Fellow, Centre for Area Studies, FreieUniversitaet, Fabeckstrasse 23-25, 14195 Berlin, Germany. Email: k.bierski@gmail.com

Ananda Balayogi Bhavanani, Deputy Director, Centre for Yoga Therapy, Education and Research

Email: yoga@mgmcri.ac.in

Eswaran S, Professor and Head Department of Psychiatry,

Email: psychiatry@mgmcri.ac.in

Madanmohan, Director, CYTER and Head, Department of Physiology, Email: drmadanmohan999@rediffmail.com

Sri Balaii Vidyapeeth - Mahatma Gandhi Medical College and Research Institute Campus Pillaiyarkuppam, Puducherry - 607403, INDIA

\begin{abstract}
This article explores how patients and their families engage with yoga practice offeredat a psychiatric ward of MGMC\&RI in the Sri Balaji Vidyapeeth in Pondicherry, India. The material collected during participant observation-based research in form of detailed field notes, photography and video focused on patients' experiences, hopes and limitations as well clinical staff's expectations and opinions on providing yoga as a therapeutic activity. Participants in the study found yoga to be a beneficial practice through which they could release tensions, relax and care for themselves. However, patients also felt that they would not be able to continue with their practice once discharged from the hospital. In addition to therapeutic interventions, then, there is a burning need to introduce yoga in patients as a long-term skilled practice. Yoga could be brought out of the psychiatric ward into the patients' day-to-day lives by encouraging families to practice together. Furthermore, we suggest that using personalised videos could support patients in maintaining regular practice and to enhance adherence.
\end{abstract}

Key Words: Yoga, Psychiatry, Mental Health, Anthropology. 


\section{INTRODUCTION}

Research on remedial applications of yoga in mental health problems has focused, among other issues, on exploring yoga's efficacy in the treatment of depressive symptoms $s^{1,2}$ or improving cognitive functions among the elderly ${ }^{3-4}$. Researchers have also investigated yoga's therapeutic potential in functional disorders such as schizophrenia ${ }^{5-6}$, cognitive functions in geriatric patients ${ }^{7}$, treatment of children ${ }^{8}$ or distress relief among victims of natural disasters ${ }^{9-10}$.

While the existing research tends to focus on assessing the outcomes of yoga "interventions" in targeting particular conditions or symptoms, very little attention has been paid to the subjective perspectives of patients, their families as well as therapists and medical professionals involved in yoga training. Quantitative data might verify the effectiveness of yoga but it fails to account for how people engage with its practices and philosophy. Current research in the field can, thus, be enhanced by attending to personal motivations, meanings given to and struggles in personal practice as well as the particularities of the context in whichyoga is introduced. This current account makes an initial step in this direction by discussing a pilot research conducted at the Psychiatry departmentof MGMC\&RI in Tamil Nadu, South India where inpatients have been introduced to yoga practices.

For a period of twenty-five days an exploratory participant observation was conducted with psychiatric patients and their families, yoga therapists, clinicians, nurses as well as postgraduate college students. Drawing on their subjective accounts, and in anticipation of the forthcoming period of the research, we discuss existing opportunities and limitations in introducing yoga to the local population in rural India. Concurrently, this report hopes to open up a discussion regarding the relevance of anthropological approaches in the field of yoga therapeutics and research and calls for a closer cooperation between specialists working in the field of psychiatry, yoga and anthropology.

\section{METHODS AND THERAPEUTIC MODEL}

This research evaluated patient care in anticipation of extending the yoga training to rural health centres. Patients in the study were informed about this goal and asked whether they are willing to share their accounts. Verbal informed consent was collected and no identifiable information is presented here.
The material collected during the pilot in form of detailed field notes, photography and video focused on patients' experiences, hopes and limitations as well clinical staff's expectations and opinions on providing yoga as a therapeutic activity on the ward. The pilot anticipated a more extensive anthropological research by contemplating feasible research questions and methodology that would be suited to the specificities of the context. The study was conducted as part of an inquiry into applications of yoga in mental health problems in a variety of settings including hospitals that offer yoga therapy as well as yoga ashrams and schools that run yoga therapy courses. The material collected in these locations is not discussed here but provided the necessary background for understanding the therapeutic uses of yoga in contemporary India on one hand and the scope of as well as challenges in psychiatric services in the country on the other.

Although yoga lessons are available to both patients and staff at the hospital through its Centre for Yoga Therapy, Education and Research (CYTER), it was proposed, bearing patients' safety in mind that classes would also be provided directly at the psychiatry ward. The treatment model was devised at CYTER under the guidance of the second author and introduced by the centre's therapists alternatively in the female and the male ward. On most days, patients of both genders practiced alongside each other. Yoga sessions would last forty-five minutes during which patients practiced a number of techniques drawn from the Gitānanda Yoga tradition (www.icyer.com). These included, among others, kayakriya (moving of legs, arms, and neck combined with attentive breathing), jattis (loosening and shaking of body parts) or śavāsana(relaxing supine pose) lying on the hospital bed. Patients were also introduced to nasargamukabastrika, a practice that entails nasal inhalation and forceful exhalation through the mouth combined with dynamic movements of limbs all of which aims at a release of bodily and mental tensions. Participants also gave attention to their breathing by learning various pranayama techniques including relaxing chandranād $\bar{\imath}$ (left nostril breathing), bbrāmarì (bee-like humming exhalation with closed mouth) as well as PranavaA-U-M chanting in both sitting and supine positions. Vyagaragage (observing inhalation and exhalation) as well as mudra(actions) such as bhramamudrā (chanting A-U-I-M with head movements) were also taught. ${ }^{1-12}$

While each of the two therapists took a slightly different approach to sequencing the class, introducing particular techniques as per patients' requirements and 
space availability, an upbeat and accepting approach was always required in building a trusting relationship with patients. By being kind and approachable, therapists encouraged patients to commit to their practice with confidence. Bearing this in mind, only minor postural corrections were given, for example, when participants would show little interest in the practice or low bodyparts awareness. Individual assistance was provided upon request.

\section{FINDINGS}

Patients at the ward where this research took place suffered from a wide range of conditions ranging from schizophrenia and bipolar spectrum disorder to depression. Instead of focusing on these criteria we asked the patients to describe how they felt. They usually answered "nervous", "stressed", "uncertain about the future", "overworked" or "tired". Understandably, the sessions would start slowly and sometimes patients needed a lot of encouraging standing up from their bed. As a practice would progress, smiles and laughs indicated that the patients found it enjoyable and worthwhile.Certain patients, but also relatives, would join only after some minutes or even on the next day having watched others practice first.A handful of patients, however, were not able to practice due to lethargy or inertia, which clinical staff interpreted as side effects of medication.

While female patients and family members would be less keen to engage in the more vigorous parts of the class, male participants found the dynamic àsana and kriya to be their favourite. A gendered difference was also noted in terms of attitudes towards relaxation techniques. Female patients, in general, enjoyed the repose more easily, whereas male patients pulled out of the experience quickly and, for example, found lying down with their eyes closed and stilling their body much more difficult than females. Even in relaxing poses, male patients would tighten their muscles, especially in their extremities. In spite of these difficulties, participants of the same gender encouraged each other and several staff members made positive remarks about bonding well as a sense of comradeship that yoga practice brought to the ward.

Throughout the research, participants reported that practicing yoga had brought them a sense of "joy", "peace", "satisfaction", "relaxation", "lightness" or "feeling of ease". For many, becoming aware of their breath and movement was unfamiliar yet it appeared to free them, at least temporarily, from tensions and worry. One young male patient called yoga sessions an "important social service" while patients who had practiced yoga in the past were happy to see it introduced in a hospital. Junior medical practitioners at the ward recounted that their patients spoke highly of the yoga classes. All in all, participants in this research reported that yoga provided a lively alternative to the otherwise mundane flow of life at the ward.

As a methodological experiment for future work, photographs and short films were taken during the practice. These were used in the ensuing discussions with patients to encourage them to reflect on their participation. Upon seeing himself in a film, a male patient in his thirties opened up about his experiences; he told of his life struggles and history of substance abuse but also about being reluctant to join the class. At first, he thought yoga was too energy consuming but, "by doing it", he actually felt "calmed" and "relaxed". Notably, it was found that the patients whom we asked to reflect on their practice engaged with more vigour and enthusiasm during the following session. Film and video recordings, in particular, made participants realise that both yoga classes and the research project had their best interest in mind.

Participating in yoga classes also provided a space for thinking about some more fundamental live issues: "would yoga make me more outgoing?", "can I improve my communication skills with yoga?", "can yoga help me relax" were some of the questions patients asked the researcher. Subsequently, it emerged that in their day-to-day lives, participants rarely engaged in sports or unwinding practices. Furthermore, the patients who worked as farmers or labourers considered partaking in physically demanding or sporting activities as neither desirable nor feasible. While most patients chose to socialise as their preferred way for relaxing, some also attended either Hindu or Muslim shrines. Notably, a number of male patients claimed to have recently stopped participating in religious activities. When asked to explain his reasons for doing so, one participant, who also recently shifted from working in agriculture to driving, responded: "I felt that I could rely on myself more". He then added that he enjoyed having a disposable income that his new employment generated. In similar vein, another male participant whose financial situation had also recently improved asserted: "I became stronger, so I did not need someone to tell me what to do anymore."

Regardless of how patients approached matters of belief, from ambivalent to downright rejection, there 
were no explicitly negative attitudes towards yoga. When asked whether he finds yoga to be compatible with Islam, one elderly Muslim patient claimed that on Friday evening he first went to a mosque and then a yoga class: "Prayer and yoga are the same", he explained, pointing out that both are a form of "surrender to a higher force" and "both are (concerned with) Manidhaneyam", the notion that is best translated as a sense of or platonic love for humanity. "Islam is asking (you) to do yoga, by doing yoga I care for myself, I become myself", he continued.

In the context of the research, relatives would often motivate patients to participate in yoga.Some relatives refused to join explaining that only their sick relatives needed to practice. They were also keen to rest from their daily duties: an elderly female explained that since her daily job was farming, she preferred to rest and avoid exertion while taking care of her hospitalised son. In cases when relatives would pressurise a patient to join in, they were encouraged to practice together. While family members often appeared shy to become involved, whenever they overcame their inhibitions they found joy and contentment in the class.

On several occasions during the research, consultants at the ward would ask therapists to suggest individual patients with techniques to alleviate some particular symptoms. Since there was a concern that patients might not be able to remember how to practice, we reached out to their families or fellow patients. A mother of a severely anxious female patient in her twenties was taught brabmaripranayama and encouraged to practice together with her daughter. Another female patient, also in her twenties, complained about insomnia. On a Saturday morning, she was introduced to some relaxing breathing techniques such as chandranadi. During a follow up after the weekend, the patient reported that her sleep only improved on Sunday night even though she practiced on Saturday only.

This incident clearly highlighted the need to pay more careful attention to how patients adhere to and evolve in their yoga practice. Clinical staff at the Department of Psychiatry shared this concern with practice continuity as they explained that patients often wanted a quick fix such as a tablet or an injection and, even though they rested during their hospital stay, they were also keen to return to their everyday lives. Crucially, in the course of the pilot project only one patient said that, once discharged, he would be able to attend regular yoga classes provided free of cost at the hospital centre. Other patients saw the distance between the hospital and their places of residence, lack of funds or time, work and family obligations as preventative.

\section{LOOKING AHEAD}

Patients hospitalised at the psychiatry clinic where this research took place experience considerable stress in their day-to-day lives and expressed concerns about their future. This is in response to work- or educationrelated pressures, family expectations as well as changes in employment especially moving away from sustenance agriculture towards wage labour or, in case of female patients, carrying a double burden of agricultural work and family care. For some patients, their decreasing interest in religious matters preceded their loss of hope. Furthermore, some saw personal income as a chance for both personal growth and family prosperity. Participants, in general, enjoyed few opportunities to talk about their mental health problems to others as mental illness continues to remain a taboo subject. Most patients come to the hospital as a last resort, when their ill-health had already advanced.

Following yoga classes, patients reported to be more "comfortable", "relaxed" and "at ease", feelings they experienced all too rarely. Even though some participants were initially reluctant to join, through practicing they could loosen up without getting fatigued. Arguably, participants found yoga practice useful because, through "doing it" they developed awareness of self in the world, removed tensions through sequencing of movements and breath and found a sense of freedom as well as satisfaction in simplicity but also repetition of practice. Patients also appreciated that therapists were positive and accommodating and did not force them into practice. By spelling out what yoga meant to them during interviews, patients gained further motivation toparticipate. They were considerably more willing to discuss difficulties they experienced, both in their life and yoga practice, once they had realised that the therapists and the researcher had a genuine interest in their accounts.

Using stills and film as a feedback mechanism was particular useful in this as, rather than trying to meet the researcher's expectations or patients' subjective perceptions thereof, participants were able to focus on their own feelings and experiences. This speaks to the observation made across the extensive literature on illness accounts, namely, that control of narratives is crucial in recovery processes ${ }^{13-16}$ or even a form of recovery in itself ${ }^{17-18}$. Yoga practice, as the next 
stage of the research hopes to explore, might provide psychiatric patients with new ways of telling their stories: not only verbally but physically, mentally and communally too. In particular there is a great potential in employing visual methods to collaboratively generate personal accounts and stories of yoga practice and using personalised videos or online communication tools to support patients in maintaining regular practice ${ }^{19-20}$ and to enhance adherence.

Stigma against mentally ill perpetuates a sense of vulnerability and social inadequacy ${ }^{21}$ and, as such, prevents healing. This is also why mental health movements, organisations and campaigns around the world have focused on eradicating discriminatory and stigmatising attitudes ${ }^{22-23}$. One method of removing stigma is to engage a broad spectrum of social actors in the recovery. The role of family in this process cannot be overstated, especially in India where patients are admitted to psychiatric wards only with an accompanying relative. We found that families played a crucial role in encouraging patients to practice and suggest that yoga could be brought out of the psychiatric ward into the patients' day-to-day lives by encouraging families to practice together. This would prevent relatives from putting pressure on the patient to recover faster, usually because engaging in care duties at the hospital leads to a loss of income. Providing training to patients and relatives could give them a sense that the time spent at the hospital was useful. First, however, a number of perceptions needs overcoming such as that yoga is only for the patient, that it is physically demanding, that illness requires a "quick fix", and that responsibility for healing rests on the shoulders of medical professionals.

While recording and publicly displaying patients' accounts in the form of posters and leaflets but also films could be helpful in providing more accurate information about yoga and its aims, this research identified a need for a systematic model of yoga education for patients and their families. Nurses who maintain extensive contact with patients are in the position to effectively guide and support them during practice. The existing yoga training that nursing students receive as part of their undergraduate degree at the medical college where the research took place provides such important educational opportunities. However, staff at the psychiatric clinic explained to require further training in yoga in order to bring a closer understanding between staff and patients.

\section{YOGA AS A SKILL}

The pilot study presented here breaks with the tendency to employ multiple regression analysis to understand therapeutic value of yoga practice by offering what, in this field, is an innovative anthropological approach. As a conclusion, limitations of this study and an outline of the intended plans for the next phase of the research are discussed. One major drawback of this pilot was its relatively short time frame. More extensive interviews with the patients and clinical staff and longer period of participant observation, also in local villages, would provide a more comprehensive picture of mental health needs and practices in the population. Translation posed another concern and, in the future, interviews with patients will be conducted in Tamil only.

While the research revealed no particular issues with implementing the yoga module itself, it exposed a concern with how patients could benefit from yoga on a long-term basis. This aim could be achieved by brining yoga training, and with it, this research, out of the clinic and to patients' everyday milieu. In their report on the scope of mental health problems in rural West Bengal, Chowdhury et a ${ }^{24}$ explained that the significant disparities in access to health care between urban and rural populations of India necessitate the development of localised mental health services. More than a decade later, their call pertains to the situation in the southern state of Tamil Nadu. The authors proposed "cultural epidemiology" as an opportune tool for understanding the conditions in which localised health care could be provided. This on-going research, meanwhile, draws on Ingold' ${ }^{25}$ suggestion that cultural difference is, essentially, a variation of skills or adaptations to the broadly defined environment that includes social life ${ }^{(26)}$. Presented with yoga as a skill, patients could develop proficiency within the realm of their own possibilities while approaching their wellbeing as an ontogenetic development ${ }^{27}$ or an ongoing process of self-transformation. 


\section{REFERENCES}

1. Gangadhar BN, Naveen GH, Rao MG, Thirthalli J, Varambally S. Positive antidepressant effects of generic yoga in depressive out-patients: A comparative study. Indian journal of psychiatry2013; 55(7): 369.

2. Naveen GH, Rao MG, VishalV,Thirthalli J, Varambally S,Gangadhar BN. Development and feasibility of yoga therapy module for out-patients with depression in India. Indian J Psychiatry 2013; 55 (Suppl 3):S350-56.

3. Hariprasad VR, Varambally S, Varambally PT, et al. Designing, validation and feasibility of a yoga-based intervention for elderly. Indian J Psychiatry2013 Jul;55 (Suppl 3):S344-49.

4. Hariprasad VR, Koparde V, Sivakumar PT, et al. Randomized clinical trial of yoga-based intervention in residents from elderly homes: Effects on cognitive function. Indian Journal of Psychiatry. 2013;55(Suppl 3): S357-S363.

5. Manjunath RB, Varambally S, Thirthalli J, Basavaraddi IV,Gangadhar BN. Efficacy of yoga as an add-on treatment for in-patients with functional psychotic disorder. Indian J Psychiatry2013; 55 (Suppl. 3): 374-78.

6. Bhargav H, Nagendra HR, Gangadhar BN, Nagarathna R. Frontal Hemodynamic Responses to High Frequency Yoga Breathing in Schizophrenia: A Functional Near-Infrared Spectroscopy Study. Frontiers in Psychiatry 2014; 5:29.

7. Umadevi P, Ramachandra S, Varambally S, Philip M, Gangadhar BN. Effect of yoga therapy on anxiety and depressive symptoms and quality-of-life among caregivers of in-patients with neurological disorders at a tertiary care center in India: A randomized controlled trial. Indian journal of psychiatry 2013; 55 (Suppl 3):S385-9

8. Uma K, Nagendra HR, NagarathnaR, Vaidehi S, Seethalakshmi R. The integrated approach of yoga: a therapeutic tool for mentally retarded children: a oneyear controlled study. J MentDefic Res 1989; 33 (Pt 5): 415-21.

9. Telles S, Naveen KV, Dash M. Yoga reduces symptoms of distress in tsunami survivors in the Andaman Islands. Evid Based Complement Alternat Med 2007; 4:503-09.

10. TellesS, Singh N, Joshi M. Risk of posttraumatic stress disorder and depression in survivors of the floods in Bihar, India. Indian Journal of Medical Sciences2009; 63(8): $330-34$

11. Giri Swami G. Yoga: Step-by-step. Pondicherry, India: Satya Press;1976.

12. Bhavanani AB,Yoga Chikitsa: Application of Yoga as a therapy. Pondicherry, India: Dhivyananda Creations; 2013.

13. Kleinman A. The illness narratives: Suffering, healing and the human condition.New York: Basic Books; 1988.

14. CharmazK. Good Days, Bad Days: the Self in Chronic Illness and Time. Sociology of Health \& Illness1992; 14(3):420-422.

15. FrankAW. The wounded storyteller: body, illness and ethics.Chicago\& London: University of Chicago Press; 1995

16. SkultansV. Authority, Dialogue and Polyphony in Psychiatric Consultations: A Latvian Case Study. Transcultural Psychiatry 2004; 41(3): 337-359.

17. Rosen Sidney. My voice will go with you: the teaching tales of Milton H. Erickson.New York\& London: Norton; 1982

18. AntzeP, Michael L. Tense past: cultural essays in trauma and memory. Abingdon: Routledge; 1996.

19. Cheung C, Wyman JF, Savik K. Adherence to a yoga program in older women with knee osteoarthritis. Journal of Aging and Physical Activity 2016;24(2): 181-188.

20. Guo SH, Lee CW, Tsao CM, Hsing HC. A social media-based mindful yoga program for pregnant women in Taiwan. Studies in Health Technology and Informatics2016; 225:621

21. Goffman E. Asylums. Harmondsworth: Penguin;1961

22. Crossley N. Contesting Psychiatry: Social movements in mental health. Abingdon: Routledge; 2006.

23. Bierski K. 'Something We All Have' - Mental health, activism and media in the United Kingdom. Special Issue Arts, Media and Cultural Mental Health. World Cultural Psychiatry Research Review 2015; 10(3-4):138-148.

24. Chowdhury AN, Chakraborty AK, Weiss MG. Community mental health and concepts of mental illness in the Sundarban Delta of West Bengal, India. Anthropology \& Medicine 2001; 8(1):109-129.

25. Ingold T. The Perception of the Environment: Essays on Livelihood, Dwelling and Skill.Abingdon: Routledge; 2000.

26. Bierski K. Recovering mental health across outdoor places in Richmond, London: Tuning, skill and narrative. Health \& Place 2016; 40: 137-144.

27. Ingold T. Prospect: death of a paradigm. In:Ingold T, Palsson G, editors.Biosocial becomings: integrating social and biological anthropology. Cambridge:Cambridge University Press;2013. 